\title{
Keloids: Current concepts of pathogenesis (Review)
}

\author{
GREGOR M. BRAN, ULRICH R. GOESSLER, KARL HORMANN, \\ FRANK RIEDEL and HANEEN SADICK \\ Department of Otolaryngology, Head and Neck Surgery, University Hospital of Mannheim, \\ University of Heidelberg, D-68135 Mannheim, Germany
}

Received October 21, 2008; Accepted December 15, 2008

DOI: 10.3892/ijmm_00000231

\begin{abstract}
Excess scar formation occurs after dermal injury as a result of abnormal wound healing. Hypertrophic scars and keloids both represent fibrotic skin conditions which can be very difficult, even frustrating, to treat. Identification of differences between hypertrophic scars, keloids and normal scars are a prerequisite for finding the correct therapeutical concept. Despite the relatively high prevalence of keloids in the general population, the mechanisms underlying keloid formation are only partially understood. This fact is reflected in the multiple treatment modalities, of which no single treatment has proven to be widely effective. Advances in our understanding of the wound healing process reveal new pathophysiological concepts for keloid formation. Our article presents an overview on physiological wound healing and the pathogenesis of scar formation, differentiates keloids from hypertrophic scars and reviews current hypotheses for keloid formation. This information might assist in deciphering the complexity of keloid pathogenesis and help in the development of an efficacious therapeutical strategy.
\end{abstract}

\section{Contents}

1. Introduction

2. Principles of wound healing

3. Classification

4. Keloids versus hypertrophic scars

5. Concepts of pathogenesis

6. Conclusion

\section{Introduction}

The skin is the largest organ in the human body. Due to its constant contact with the environment, it is able to adapt to extrinsic stresses and strains in order to protect fragile systems

Correspondence to: Dr Gregor M. Bran, Department of Otolaryngology, Head and Neck Surgery, University Hospital of Mannheim, Theodor-Kutzer-Ufer 1-3, D-68167 Mannheim, Germany E-mail: gregor.bran@hno.ma.uni-heidelberg.de

Key words: hypertrophic scars, keloids, fibrotic skin within the body against the surrounding effects. After skin wounding, an immediate and consistent initiation of repair processes begins which can be summarized as the normal healing response resulting in scar formation. In the case of a disturbance in the delicate balance of reparative processes, wound healing can be impaired drastically resulting in two pathological extremes: chronic wounds (e.g. ulcers during head and neck radiotherapy) or excess scar formation ranging from hypertrophic scars to keloids (Fig. 1).

Though many reviews outlining the similarities and differences of scar formation have been published in the last three decades, little attention has initially been given to the precise use of the terminology. Examples of the resulting interchangeability of the terms or a questionable benefit of further distinction are well illustrated in the articles of Alster and Williams (1) and McGrouther (2). This generalization had led to an incomplete understanding of the pathogenesis of different scar types.

The terms hypertrophic scar and keloid are still used interchangeably, which may lead to incorrect identification and clinical diagnosis resulting in false therapeutical regimens. However, there are many clinical, pathological and biochemical differences that suggest these structures are distinct from each other $(3,4)$.

After skin injury, an immediate and consistent initiation of repair processes must begin which can be summarized as the normal healing response which results in scar formation. In terms of surgical procedures, the competence of a surgeon is often estimated by the patient who sees the resulting scar. Handling scar tissue plays a central role in facial plastic surgery (1,5-7). Dissatisfied patients urge the facial plastic surgeon and hope to get a perfect result with no scar tissue left after the therapy is finished. The facial plastic surgeon is double challenged; besides a minimization of the unrealistic conception of the patient, a very difficult tissue needs to be classified correctly and treated with the most promising therapeutical strategy.

Keloidal scarring is one of the most frustrating problems in wound healing. Clinically, keloids are defined as scars that invade adjacent healthy tissue and rarely regress over time. They tend to occur in darker skinned individuals with a familial tendency and not in extremes of age $(8,9)$.

Advances in our understanding of the similarities and differences of keloids and hypertrophic scars might help in the development of efficacious strategies for prevention or treatment. 


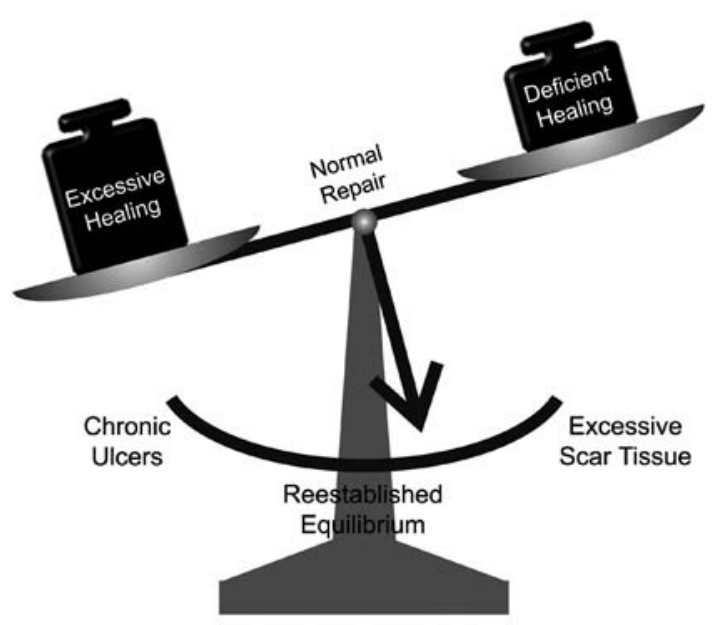

Figure 1. Any disturbance of the delicate balance of normal wound repair leads to a disruption of anatomical structure and function.

\section{Principles of wound healing}

Understanding the basic principles of wound healing is an essential prerequisite for elucidating the molecular differences in the pathophysiology of scar tissue formation. The term 'wound' is defined as a disruption of normal anatomical structure, and more importantly, its function (10-12). Therefore, healing is a complex and dynamic process that results in the restoration of anatomical continuity and function (13). Skin wounding triggers a highly complex cascade of local and systemic events that follow a specific time sequence and can be categorized into four distinct, but overlapping phases: hemostasis, inflammation, proliferation and remodeling (10). A normal healing response results in scar formation. However, in the case of a disequilibrium of reparative processes, wound healing can be impaired drastically resulting in two pathological extremes: deficient healing leading to chronic wounds (e.g. ulcers caused by head and neck radiotherapy) or excessive healing due to surplus deposition of connective tissue (e.g. hypertrophic scars or keloids) (Fig. 2).
The healing cascade begins the moment the skin is injured. Through bleeding, blood components are spilled into the wound site. Platelets come into contact with exposed collagen and different elements of the extracellular matrix. This contact triggers the release of important growth factors such as the transforming growth factor $\beta$ (TGF- $\beta$ ) or platelet-derived growth factor (PDGF), and clotting factors initiate the repair process. Clotting takes place in order to obtain hemostasis, which is the initiating reaction of the first phase of wound healing. The result is the deposition of a fibrin clot at the site of injury which serves as a provisional matrix for subsequent events of healing. The above mentioned growth factors are the two most important cytokines which initiate further steps along the healing cascade. PDGF induces chemotaxis of neutrophils, macrophages, smooth muscle cells and fibroblasts. It also stimulates the mitogenesis of fibroblasts and smooth muscle cells. TGF- $\beta$ attracts macrophages and stimulates them to secrete additional cytokines. It also enhances fibroblast and smooth muscle cell chemotaxis and modulates collagen and collagenase expression (10). According to the overlap principle of wound healing phases, the result of this signaling can mainly be observed in the proliferative phase which follows the inflammatory phase.

Within 24 hours after injury, inflammation is increased by neutrophils which enter the wound site and remove foreign material, bacteria, non-functional host cells and damaged matrix components by means of phagocytosis (14). This phase can last up to 8 days (11). Beside neutrophils, mast cells are another marker cell during this phase. They release enzymes, histamine and other active amines which are responsible for the characteristic signs of inflammation around a wound site (rubor, calor, tumor, dolor and subsequently functio laesa). Interestingly, fibrotic lesions are often associated with increased densities of mast cells $(10,15)$. Within $48 \mathrm{~h}$ after injury, monocytes are activated to become wound macrophages. These cells are discussed to be the most essential inflammatory cells involved in the normal healing response. Their presence is a marker for the nearing end of the inflammatory phase and the beginning of the proliferative phase (16). Inhibition of macrophage function results in a delay of the

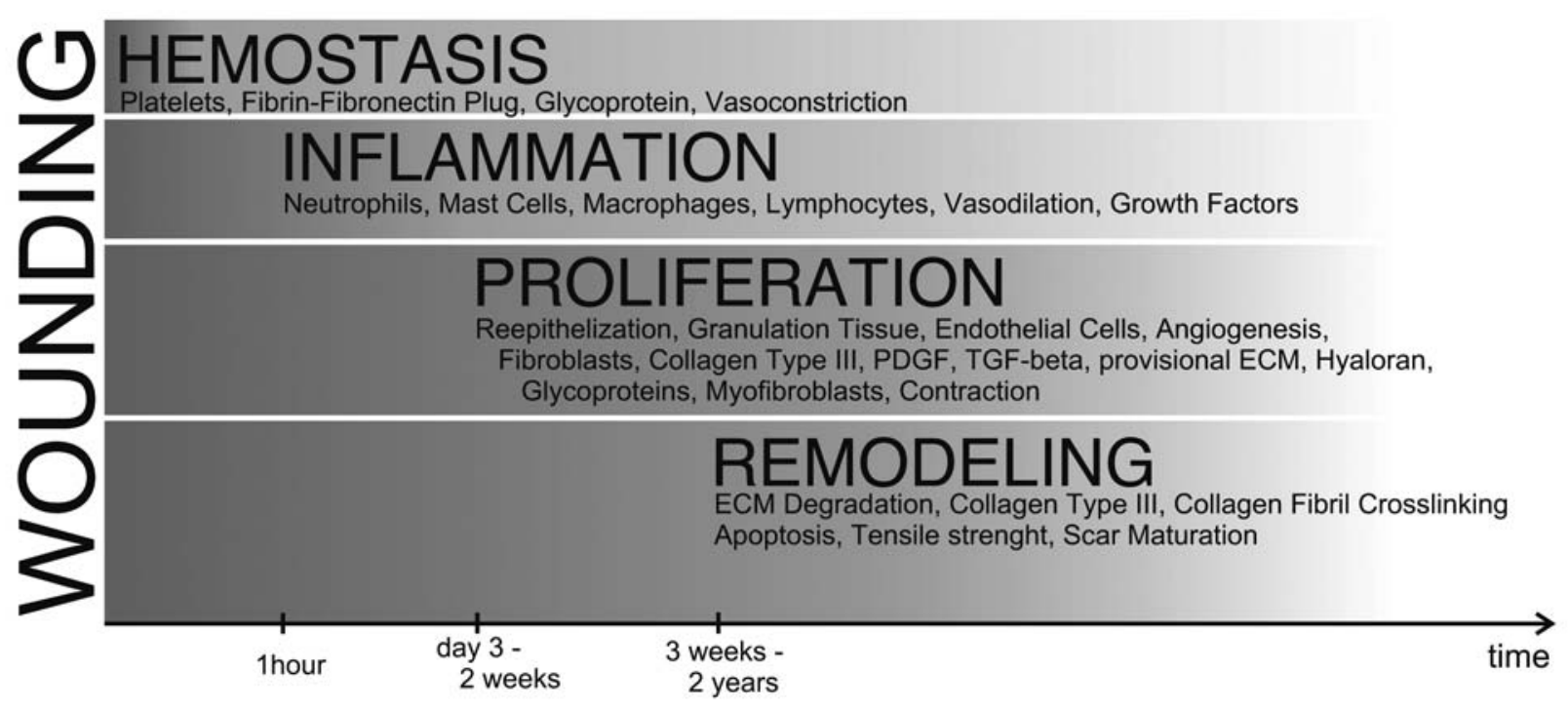

Figure 2. Sequence of events during physiological wound healing. 


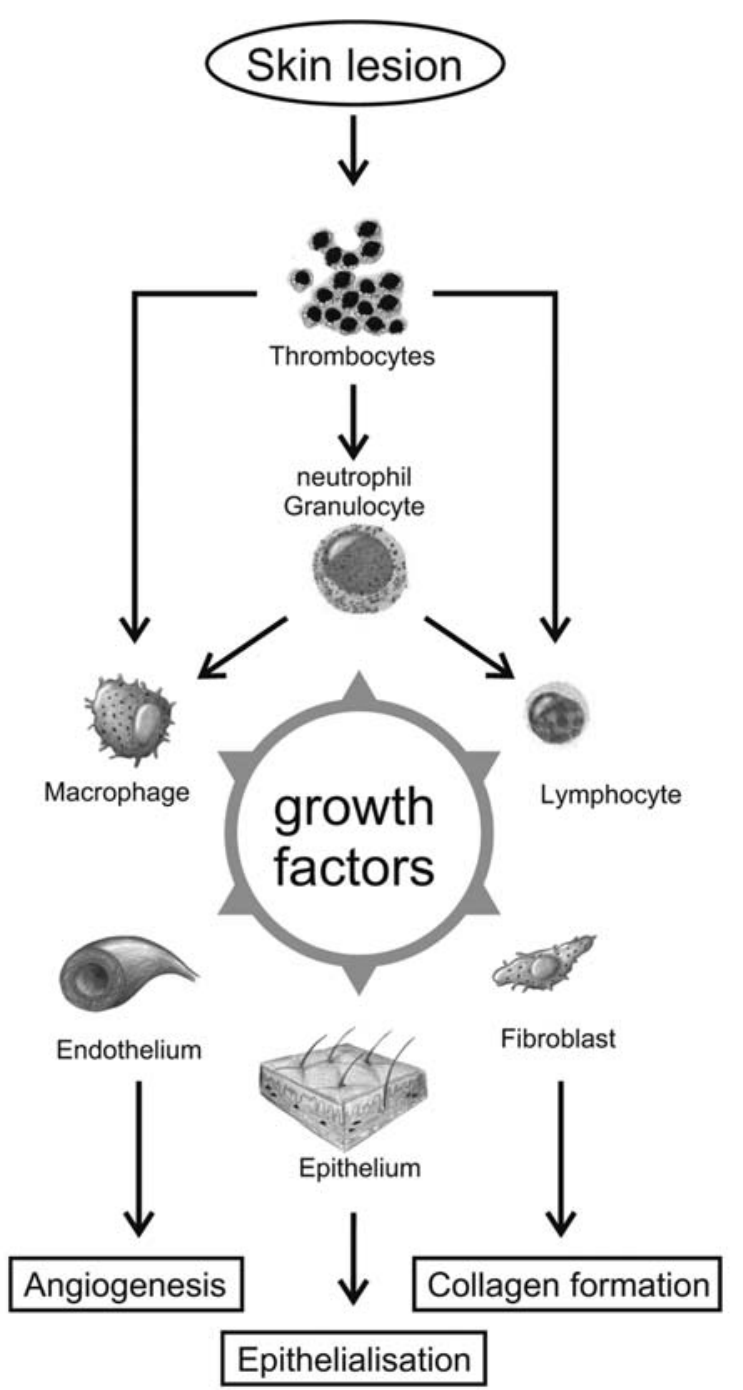

Figure 3. The central role of growth factors in physiological wound healing.

healing response. Macrophages continue phagocytosis and release PDGF and TGF- $\beta$ further attracting fibroblast and smooth muscle cells to the wound site.

Once the wound site is cleaned, the proliferative phase begins with fibroblast migration and deposition of new extracellular matrix which is needed to restore structure and function of the injured tissue. As the proliferative phase progresses, the concerted release of TGF- $\beta$ by different cell groups becomes the master control signal that regulates a multitude of fibroblast functions $(17,18)$. Fig. 3 summarizes the central role of growth factors within physiological wound healing.

During the proliferative phase (from day 8 to day 14 after skin injury) fibroblasts are the predominant cells attaching to the provisional fibrin matrix following proliferation and collagen deposition (19). Collagen deposition is important because it increases the strength of the wound. As collagen production continues, collagenases and other factors degrade it. Initially, the level of production exceeds the rate of degradation, but later a homeostasis is gained. The equilibrium between collagen production and degradation signals the onset of the next phase. Fibroblasts, stimulated by growth factors, also differentiate into myofibroblasts, which are similar to smooth muscle cells and responsible for wound contraction. As the myofibroblasts contract, the wound edges are pulled together which results in a reduction in wound size and an increase in tensile strength in the wound region $(12,20,21)$. Deposited collagen reinforces the contracting wound site. At the end of contraction, myofibroblasts stop their activity and commit apoptosis $(22,23)$. The parallel breakdown of the provisional matrix triggers fibroblasts to stop migrating and proliferating. The phase of maturation and remodeling begins. The maturation phase can last for a year or longer, depending on the initial size of the wound and whether it was closed or left open (24). During this phase, type III collagen, which is predominant in the proliferation phase, is degraded and substituted by the stronger type I collagen. In comparison to collagen in normal tissue, newly formed collagen fibers are smaller and have a random appearance. Initially, disorganized collagen fibers are rearranged, cross-linked and aligned along tension lines (21). Thereby the tensile strength of the wound increases. However, a mature scar will never return to the high degree of organization of normal dermal architecture, therefore scar tissue is always weaker than the surrounding normal tissue with a maximum tensile strength of approximately $80 \%$ of normal skin $(10,25)$. At the end of maturation, the activity at the wound site is reduced, blood vessels are removed by apoptosis and the scar loses its erythematous appearance $(21,22)$.

Succession and intensity of every healing phase is mainly controlled by growth factors and different cytokines $(11,26)$. The application of cDNA microarray analysis provides a powerful tool to investigate differential gene expression in pathological scar tissue, uninjured skin or normal scars. The resulting broadscale evaluation may not only identify different or new molecules that play an important role in scar pathology but also their relevant period of time within the above mentioned overlapping phases of wound healing $(27,28)$. New findings gathered hereby may clear the way for promising concepts of genetic therapy simulating or enhancing physiological processes in order to optimize wound healing in difficult skin wounding conditions.

\section{Classification}

The fundamentals of wound healing seem to be decoded; however, the exact mechanism of wound healing regulation remains a mystery. The ideal scar should be similar to a fine line with a pigmentation related to the neighboring healthy tissue, without any irregularities in texture or contractures distorting the adjacent skin.

Despite the fact that all of these phenomena have been described in many publications, the present knowledge of scar formation seems not to be sufficient for a highly effective transfer into clinical routine. The practical application still constitutes a major challenge for the facial plastic surgeon, particularly as it relates to abnormal scarring (3). A precise prognosis for the resulting scar or identification of risk factors and prevention of pathological scar formation remains very difficult. Scar formation is influenced by a multitude of factors such as location, pathogenesis (trauma, burn, surgery), relevant pre-treatment (operative techniques or radiation), 
Table I. The main differences between keloids and hypertrophic scars.

\begin{tabular}{|c|c|c|}
\hline & Keloid & Hypertrophic scar \\
\hline Incidence & Rare & Frequent \\
\hline Associated skin type & $\begin{array}{l}\text { Higher prevalence in dark-pigmented } \\
\text { populations }\end{array}$ & None \\
\hline Foregone skin injury & Yes & Yes \\
\hline Typical site & Everywhere; most frequently ear lobe, sternum & Everywhere \\
\hline Spontaneous regression & None & Frequent \\
\hline Recurrence after surgical excision & Almost 100\% & None \\
\hline Contracture & Seldom & Often \\
\hline Expansiveness & Infiltrates adjacent normal dermis & Confined to wound tissue \\
\hline Time relation of appearance & $\begin{array}{l}\text { Appearance after symptom-free interval, } \\
\text { proliferation without quiescent } \\
\text { or regressive phase }\end{array}$ & $\begin{array}{l}\text { Emergence within } 4 \text { weeks, } \\
\text { intense grow for several months, } \\
\text { then regression }\end{array}$ \\
\hline Orientation of the collagen fibres & $\begin{array}{l}\text { Hypocellular collagen bundles, } \\
\text { fibres are larger, thicker, } \\
\text { more wavy, random orientation }\end{array}$ & $\begin{array}{l}\text { Parallel orientation to the } \\
\text { epidermal surface }\end{array}$ \\
\hline Myofibroblasts & None & Abundant nodules \\
\hline Collagen & Increased ratio of type I to type III & Primarily collagen III \\
\hline$\alpha(\mathrm{I})$-procollagen & $\begin{array}{l}\text { Increased gene transcription } \\
\text { and protein synthesis }\end{array}$ & $\begin{array}{l}\text { Only increased mRNA } \\
\text { concentration, compensation at } \\
\text { the posttranscriptional level }\end{array}$ \\
\hline
\end{tabular}

relevant chronic illnesses, gender, gravidity, age, race, skin type or even lifestyle (sun exposure, smoker versus nonsmoker). Major limiting factors during the healing process are tensile forces acting on the wound area or wound infection. Wound healing in adult human skin results in varying degrees of scar formation, ranging clinically from asymptomatic scars, to scars that are solely noticeable and problematic scars that are accompanied by functional confinement (29). Scarring, even in terms of non-pathological aberrances, remains an individual process which can be subdivided into a spectrum of nuances. As a result, a number of scar classification schemes have been established in plastic surgery literature describing main groups of wounds ranging from normal mature scars to major keloids, with linear and widespread hypertrophic scars placed somewhere near the middle $(4,7,30)$ (Table II).

\section{Keloids versus hypertrophic scars}

A mature scar is light-colored, a flat fine line which only rarely entails functional deficits of the surrounding tissue. In most cases no therapy is required for functional reasons. As summarized in Table I, keloids and hypertrophic scars are separate clinical and histochemical entities $(4,8,11,31)$. The first challenge to effective scar therapy must be taken seriously which is the correct identification and diagnosis of problem scars.
In cases of hypertrophic scars, the wound healing process begins with normal scarring, but the accumulation of repair matrix occurs for a longer phase, with increasing morphologic and biochemical abnormality. Hypertrophic scars are typically red or pink in color, often pruritic, elevated but remaining within the confines of the original wound, induced either by trauma or surgery $(8,32)$. The first occurrence is usually several weeks after surgery. The time course is considerably prolonged in comparison to the normal scar cycle. Often it effects the scar as far as form and function are concerned, particularly when caused by contraction, which is worse than the effects in a mature scar (25). However, after a rapid increase in size, a static phase begins which spontaneously passes into a regression period $(3,7)$. The maturation process of hypertrophic scars can take up to two years time. In contrast, keloid scarring does not follow the same pattern of evolution, stabilization and involution. Keloids may appear directly after an initiating event or start to grow some years later arising from a mature scar. The latter characteristic suggests some kind of activity within mature scar tissue, even though the relevant outside influences and the potential extent of alteration are not yet known. Keloids usually present in individuals between 10 and 30 years of age and are less frequent at the extremes of age (3). Although the keloid reaction is less intense than in hypertrophic scars, the continuous proliferation surpasses the growth of hypertrophic 
Table II. Scar classification. ${ }^{\text {a }}$

\begin{tabular}{ll}
\hline Scar type & \multicolumn{1}{c}{ Characteristics } \\
\hline Mature scar & A light-colored, flat scar. \\
Immature scar & A red, sometimes itchy or painful, slightly elevated scar. Many of these \\
& will mature normally and become flat with a pigmentation similar to the \\
& surrounding skin. \\
& (Surgical or traumatic anamnesis). A red, raised, sometimes itchy scar \\
Linear hypertrophic scar & confined to the border of the original skin incision. Usual occurrence within \\
& weeks after surgery. Rapid increase in size for 3 to 6 months and then, \\
& after a static phase, regression. Full maturation process can take up to \\
& 2 years resulting in an elevated, slightly rope-like appearance. \\
& (Burn anamnesis). A widespread, red, elevated, sometimes pruritic scar \\
confined to the borders of the burn injury. & A focally raised, itchy scar extending over normal tissue. Possible \\
development up to 1 year after injury and with no spontaneous \\
regression. Surgical excision is often followed by recurrence. \\
Large, elevated (>0.5 cm) scar, possibly painful or pruritic, \\
Minor keloid
\end{tabular}

${ }^{a}$ Modified from Mustoe, 2002 (7).

scars and exceeds in size by indefinite progression (8,33-36). As a result, keloids are characterized by exuberant, erythematous scars, which grow beyond the confines of the original wounds and rarely regress over time (9) (Fig. 4). Besides their variable extent of elevation, keloid scars can become very painful or pruritic. Major keloids show elevation levels of more than $0.5 \mathrm{~cm}$ above the skin surface. An inactive keloid shows cessation of scar growth but no degeneration of the elevated tissue $(4,11,30)$. Furthermore, the resulting disfigurement not only leads to a cosmetic nuisance, but often results in a significant burden for the patient $(8,9,37,38)$.

Histopathology. In clinical practice, the histopathological diagnosis is regarded to provide the arbitration of highest accuracy. This is not universally valid as far as scar pathology is concerned. The histological analysis is complicated by common matrix morphology and cellular function in the early phases of keloids and hypertrophic scars (39). Although pathological scarring is conditional on morphological and functional changes, which eventually can be identified at one point in time, these alterations do not occur simultaneously within the entire scar tissue. Therefore, the major obstacle of histopathological scar analysis is the correct sampling and the precise characterization of the cell or tissue source (25).

Hypertrophic scars and keloids begin with a similar morphology, with the hypertrophic scar phasing through a proliferative to a static state with collagen that is increasingly organized. Keloids invade surrounding normal dermis, which differentiates them from hypertrophic scars that may appear overgrown, but histologically do not extend beyond the margins of the wound tissue $(3,39)$. Both types of scars show increased deposition of collagen and proteoglycans within the dermis and the subcutis. A common characteristic is the increased fibroblast density, but only keloids have increased fibroblast proliferation rates $(8,37)$. The collagen bundles in the dermis of normal mature scar tissue appear relaxed and in an unordered arrangement. Collagen bundles of hypertrophic scars and keloids are stretched and aligned in the same plane as the epidermis $(9,30)$. Hypertrophic scars contain primarily type III collagen with abundant nodules containing myofibroblasts and large collagen filaments. In contrast, keloids consist of type I and III hypocellular collagen bundles without any myofibroblasts (40). A histological characteristic of hypertrophic scars is the presence of nodules containing a high density of cells and collagen $(39,41)$. These nodules are located within the middle or deeper layer of the scar. The absence of such nodules is typical for keloids (42). The histological appearance of keloids is characterized by a broad dermis. Collagen fibers in keloids are larger, thicker and more wavy than in hypertrophic scars or normal mature scars and form acellular node-like structures in the deep dermal portion of the lesion $(8,9,39,41)$. The acellular core is surrounded by a concentration of hyperproliferating fibroblasts and contains thick bands of immature collagen that are poorly vascularized. The presence of large, broad, closely arranged collagen fibers, also parallel to the epidermis and composed of numerous fibrils is accepted to be the most consistent histologic distinguishing characteristic of keloids $(25,30,41)$.

Butler et al summarized four histologic features that are consistently found in keloid specimens and therefore are deemed pathognomonic for keloid diagnosis: the presence of keloidal hyalinized collagen, a tongue-like advancing edge underneath the normal-appearing epidermis and papillary dermis, horizontal cellular fibrous bands in the upper reticular dermis, and prominent fascia-like fibrous bands (30).

Besides morphological differences there are also similarities between both scar forms. Hypertrophic scars and keloids show a reduced collagenase activity and an increased 

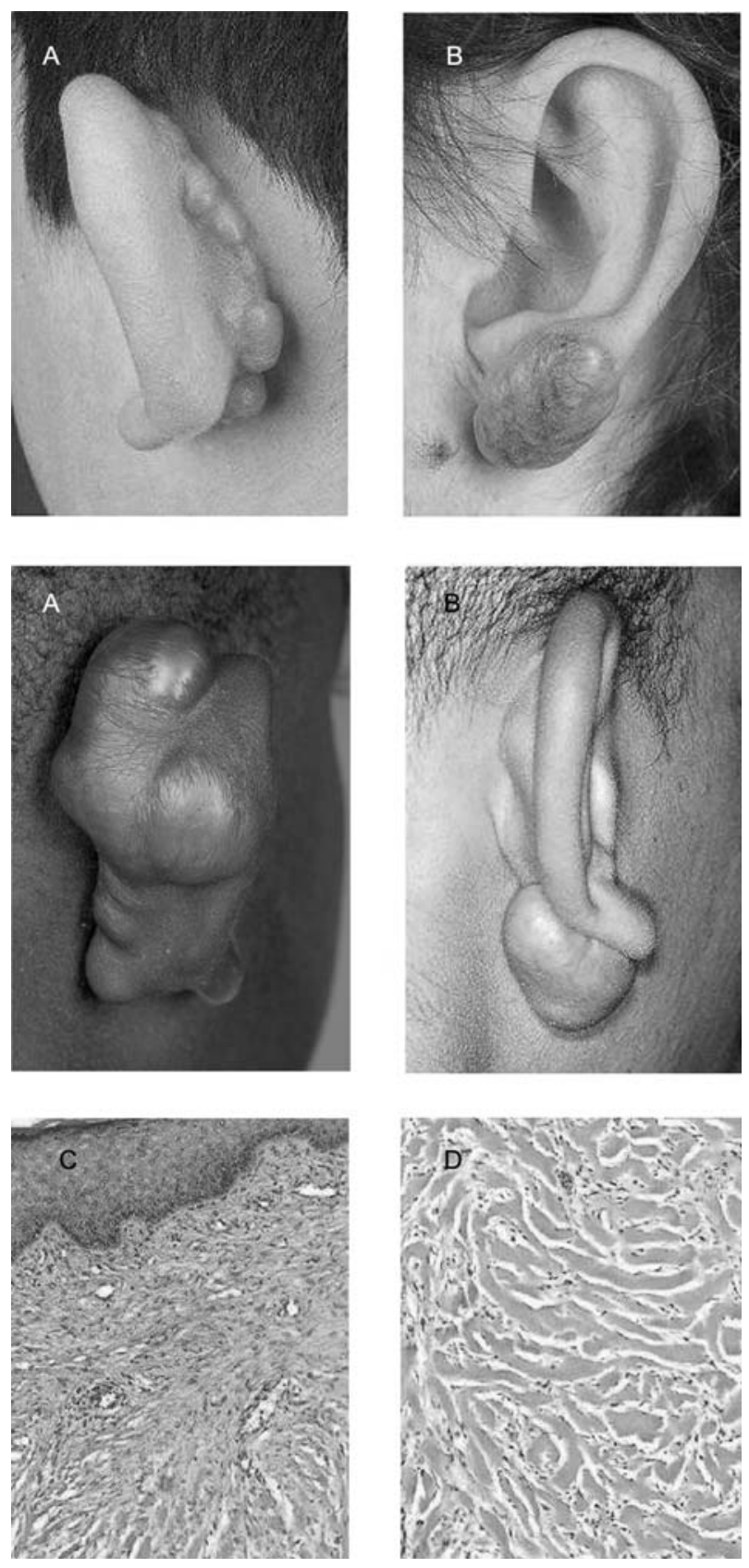

Figure 4. Keloid formation after anthelixplasty (A) or piercing of the ear lobe (B). Histological picture of a keloid (C) with enlarged collagen fibres within the dermis (D).

activity of prolinhydroxylase. Furthermore, evidence for elevated levels of chondroitin-4-sulfate have been found, which encloses collagen and thereby protects it against proteolytic processes (43). Both types of skin abnormalities are unique to humans and are characterized by excessive deposition of collagen in the dermis and subcutaneous tissues secondary to skin injuries. Both lesions demonstrate overproduction of multiple fibroblast proteins suggesting either persistence of wound healing signals or a failure in appropriate downregulation of wound healing cells.

Hypertrophic scars result from injury to the deep dermis, particularly traumatic wounds and wounds that manifest a prolonged phase of inflammation and fibroplasia (9). Keloid formation has been associated with different mechanisms. To date, no single unifying hypothesis adequately explains the entire background of keloid formation.

\section{Concepts of pathogenesis}

Two factors are generally regarded as key factors for keloid formation: genetic predisposition and skin lesion. Although clinical observations established the above mentioned factors to be the generally accepted pivotal criteria for keloids, detailed knowledge of the pathophysiological background is scarce and the most important question remains unanswered. What is the central triggering stimulus for the cascade of events causing the formation of keloids? Is the stimulus constant or does it alter? The following section presents hypotheses that have been proposed to explain the keloid phenomenon, in respect to already acknowledged factors and others not yet approved elements with potential impact on the pathogenesis of keloid formation.

Genetics and immunology. It has been estimated that keloids most frequently occur among 15-20\% of Blacks, Hispanics and Orientals and less commonly in Caucasians. There appears to be a genetic predisposition to keloid formation $(8,38)$ in the darker skinned. So far no keloid formation has been described in albinos (11). Melanocytes could play an important role in keloid formation, however subsequent study is required.

Most cases occur sporadically, although a positive family history is not unusual (44). Linkage analyses were performed to identify the chromosomal location of the predisposing gene. So far no specific gene has been linked to the development of keloids. Marneros and coworkers studied families with an autosomal dominant inheritance pattern of keloids. The gene scans provided first evidence for keloid susceptibility loci on chromosomes 2q23 and 7p11 (45). Familial tendencies suggest a polygenic inheritance pattern. However, darker complexion does not correlate with a higher rate of keloid formation, as seen in a study of 175 Malaysian keloid patients $(8,46)$.

The human HLA status is believed to potentiate the development of keloid phenotypes. Initial findings indicate a relevant association of the HLA-types: HLA-DR5, HLADQw3, HLA-DQA1 and HLA-DQB1 with keloid formation $(47,48)$. Various gene polymorphisms encoding for the TGF- $\beta$ subtypes $\beta-1, \beta-2$ and $\beta-3$ as well as the TGF- $\beta$-receptor have been evaluated in Caucasian patients, without any evidence of statistically significant associations with keloids (49-52). It is likely that mutliple genes impart susceptibility to keloid development, with different genes contributing to keloid formation in different families (38). The simultaneous analysis of multiple genes gave new insight into keloid pathogenesis. Thereby, increased expression of fibronectin and the $\alpha-1$ chain of type I collagen proteins was found, both being commonly associated with pathological wound healing. A comparison of expression levels between healthy skin fibroblasts and keloid fibroblasts showed elevated levels of the proto-oncogenes bcl-2, c-jun and c-fos, and no expression of the tumor suppressor gene p53 in keloid fibroblasts (53). The level of p53 is highest in keloids when compared to normal and hypertrophic scars (54). The two oncogenes ribosomal protein 18 and Stat-3, both important proteins for cell proliferation, may be linked to keloid pathogenesis $(55,56)$. 
Another important factor related to keloid formation may be a dysregulation of apoptosis $(57,58)$. If keloid fibroblasts fail to undergo physiologically programmed cell death and, thus, continue to produce and secrete connective tissue beyond the period expected in normal scar formation, the hypertrophic and progressive nature of keloids may result (59). It was noted that normal skin fibroblast cultures have a 2 -fold higher percentage of apoptotic cells than keloid fibroblast cultures (60). Furthermore, expression of apoptosisrelated genes, e.g. DAD-1 (defender against cell death 1) or TRADD (TNF R-1 associated death domain), is significantly reduced in keloid fibroblasts (59). Seifert et al found an upregulation of the apoptosis inhibitor AVEN at the margin of keloids, while apoptosis-inducing genes such as ADAM12 and genes inducing extracellular matrix degradation such as matrix metalloproteinase-19 were upregulated in the regressing keloid center (61).

Keloids are associated with particular human leukocyte subtypes (8). An inherited abnormal immune response to dermal injury opens up another perspective in the pathogenesis of keloid formation. A genetic influence might be directed through an immune phenotype. Immunological alterations were documented by various research groups. In comparison to healthy skin, patients who develop keloids have a high incidence of allergic diathesis and elevated levels of serum concentrations for the immunoglobulins $\operatorname{IgG}, \operatorname{IgA}$ and $\operatorname{IgM}(8,47,62-65)$. Multiple studies found trends in the patterns of serum complement and immunoglobulin $\mathrm{G}$ and immunoglobulin M levels in keloid-forming patients (62-64). Clinical evidence also suggests an inherently hypersensitive cell-mediated immune system in keloid patients $(8,63)$. In line with the immune-response hypothesis, Appleton and coworkers noted numerous apoptotic cells at the interface between dermis and keloids, a feature characteristic of cellmediated immune attack (57). The resulting considerations vary from a local immune reaction to an autoimmune connective tissue disease $(64,66)$.

Neutrophils and mast cells are the marker cells during the inflammatory phase of physiological wound healing. Interestingly, fibrotic lesions are often associated with increased densities of mast cells $(10,15)$. The release of cytokines, particularly interleukins and TGF- $\beta$, stimulates mast cell chemotaxis and fibroblast production of collagen. Skin injury exposes the pilosebaceous unit to systemic circulation, and in sensitive individuals this stimulus triggers T-lymphocyte recognition and proliferation of antigenspecific T-lymphocytes similar to a delayed-type hypersensitivity reaction (67). This process continues as the keloid growths and further pilosebaceous units on the advancing border are disrupted $(68,69)$. Memory cells develop which initiate larger secondary immune responses. The sebum hypothesis explains the distribution and behavior of keloids. Keloids affect only humans, as animals do not have comparable sebaceous glands. They do not occur on the palms and soles since these areas are devoid of sebaceous glands. Keloids occur in adolescence and early adulthood when sebum production is maximal (68). Patients with keloids demonstrate a positive skin reaction to intradermal sebum antigen with sebum vaccine being able to successfully desensitize the antigens from keloid recurrence after excision (69).
Skin lesion. It is widely accepted that keloids develop subsequently to injury or inflammation of the skin. Keloids most often occur in a setting of surgical or non-surgical wound healing. They can also occur after minor insults to the skin (e.g. mosquito bite or vaccination) or inflammatory skin conditions (e.g. acne vulgaris, folliculitis, varicella infection) $(6,35,38,70)$. Sometimes, patients may not recall an inciting trauma or inflammatory process. The causative event may remain unrecognized or forgotten, as the perniciousness of keloidal pathology may be their occurence after a long lasting uneventful interval.

During physiological wound healing, mechanical tension accumulates within the contracting wound site. Mechanical tension on a healing wound stimulates fibroblast proliferation and increases the synthesis and deposition of collagen, citing sites of keloid predilection in areas of increased tension (e.g. chest, deltoid and back) (32,71-73). Skin tension could be the reason why keloids occur in young people and are almost absent in the elderly, whose skin characteristically has poor tension $(32,68)$. Calnan and Copenhagen observed a regression of keloid tissue after autotransplantation of keloids to the anterior abdominal wall, a site of little wound tension (74).

In vitro and in vivo studies suggest that mechanical strain not only promotes collagen synthesis but also dictates collagen architecture and orientation as well as dermal remodeling (75). The physiological orientation of collagen is perpendicular to muscle contraction. Therefore, incisions performed perpendicular to the muscle contraction, and parallel to the relaxed skin tension lines, will heal with no or little collagen distortion (Fig. 5), whereas non-aligned tension forces due to an inadequate choice of incision line or scars placed at sites of high tension (e.g. flexor surfaces) will very likely result in pathologic scar formation (8). Wang et al compared the effects between normal and keloid fibroblasts subjected to mechanical strain. They observed an increased expression in TGF- $\beta 1,-\beta 2$, and collagen I in keloid fibroblasts. Additionally, there was increased formation of focal adhesion complexes with increased activation of focal adhesion kinase, a signaling component of the focal adhesion complex (76).

However, sites of frequent keloid formation (e.g. earlobe or chest) which are not generally accepted to be under tension also exist (32). Although stretch and tension are important parameters of the final appearance of the scar, they are more likely to play a role in hypertrophic scar formation than they do in keloid formation $(8,75)$.

Extracellular matrix. The extracellular matrix (ECM) plays a pivotal role in healthy skin physiology as well as in wound healing reactions. The predominant cell of scar tissue is the fibroblast, which is responsible for collagen synthesis and other extracellular matrix components including enzymes which are involved in the remodeling process. Cellular gene expression is controlled by adhesive interaction of connective tissue cells with their surrounding ECM. The contact of fibroblasts with the surrounding ECM is established by integrin receptors $(77,78)$. Integrin expression is influenced by cytokines such as TGF- $\beta$. The integrins $\alpha 1 \beta 1, \alpha 2 \beta 1$ and $\alpha 3 \beta 1$ have been described as binding to collagens, with some members such as laminin $(\alpha 1 \beta 1)$ or fibronectin $(\alpha 3 \beta 1)$ also binding to other ECM components. A major fibronectin 

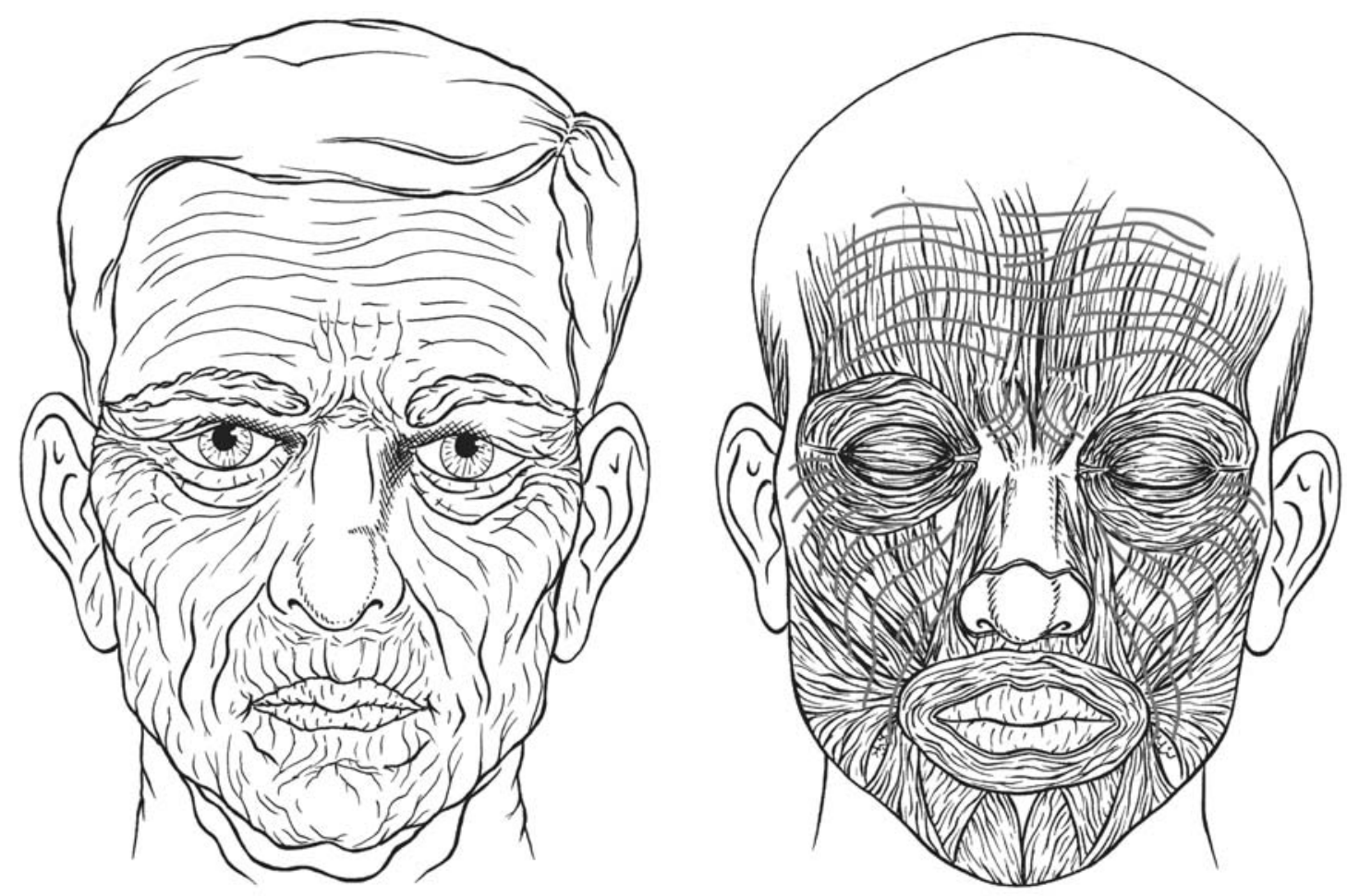

Figure 5. The relaxed skin tension lines correspond to the skin folds of an aged face (left) and run perpendicularly to the facial musculature (right).

receptor is the integrin $\alpha 5 \beta 1$ which is also known to be expressed by fibroblasts (79). Integrin expression is regulated by cytokines and growth factors released from the ECM through limited proteolysis or from adjacent cells by autocrine and paracrine mechanisms $(9,37,78)$. On fibroblasts, collagen recognition is mainly achieved by $\alpha 1 \beta 1$ and $\alpha 2 \beta 1$ integrins. Several findings suggest that binding of $\alpha 1 \beta 1$ integrin to collagen I results in an almost complete arrest of collagen synthesis according to a negative feedback regulation mechanism (80). Antibody blockage of $\alpha 1 \beta 1$ integrin prevents downregulation of collagen synthesis (81). Binding of $\alpha 2 \beta 1$ integrin has no effect on collagen synthesis (77). An abnormal reduction in $\alpha 1 \beta 1$ expression could result in a loss of the negative feedback which could explain the increased collagen synthesis within keloid tissue. However Szulgit et al (79) observed the greatest expression of $\alpha 1 \beta 1$ integrin in keloidal fibroblasts. This finding might be due to the influence of the profibrotic cytokine TGF- $\beta$ which is found in elevated concentrations in the ECM of keloids, and has been shown to upregulate surface integrin expression (82). So far little research has been conducted on the expression of integrins within keloidal lesions. Further study is required to understand the correlation between the ECM milieu and the maintenance and function of fibroblast integrin expression.

An essential feature of tissue repair and remodeling processes is the proteolytic degradation of the ECM. Within the remodeling phase during wound healing, collagen III is substituted by collagen I, proteoglycans are synthesized and fibrin and fibronectin are degraded. The two major groups of ECM-degrading enzymes are the serine proteinases, including tissue plasminogen activator (tPA) and urokinase plasminogen activator (uPA), and the matrix metalloproteinases (MMPs).
They interact and form a lytic cascade for ECM remodeling (9). MMP-1 (collagenase-1), -8 (collagenase-2) and -13 (collagenase-3) degrade collagen types I, II and III by proteolysis of the triple helix (83). The major function of the plasminogen activator is the control of activation of plasminogen into plasmin. Plasmin is the primary effective enzyme in fibrinolysis. It also activates procollagenase into collagenase and participates in other breakdown processes of ECM proteins. The initiation of the proteinase cascade by plasminogen activator results in an important amplification of proteolytic activity (9). The complexity of the entire system can be visualized by the control feedback loop of plasmin, which also induces the release of active TGF- $\beta$ from its latency-associated protein (84). The released TGF- $\beta$ regulates plasminogen activator inhibitor-1 (PAI-1), matrix metalloproteinases, tissue inhibitor proteinases-1 (TIMP-1) and genes encoding ECM components and their integrin receptors (9).

The formation of the extracellular matrix is carried out by the synthesis of collagen, fibronectin and proteoglycans, all conducted by fibroblasts (31). A deficient synthesis of products that promote matrix degradation or an excessive matrix synthesis, or both, explain the lack of scar regression in keloids $(3,85)$. Collagen degradation is mediated by MMPs. TGF- $\beta$ modulates the expression of MMPs (86). TGF- $\beta$ is known to induce the expression of MMP-2, -9 and -13 in fibroblasts, whereas MMP1 expression is negatively regulated through SMAD 3 and 4 (87). The extracellular matrix of keloids shows elevated levels of fibronectin and proteoglycans as well as MMPs. Neely et al reported significantly increased MMP-2 activity in keloids and no change in MMP-9 activity (88). Besides elevated levels of MMP-1, -2 and TIMP-1 
Fujiwara et al found an increase in the production of MMP-1 and -2 , but no influence on TIMP-1, after addition of TGF- $\beta 1$ to cultures of keloid fibroblasts (89).

As recent developments in molecular therapy offer exciting prospects for the modulation of matrix turnover, continuing investigation concerning the effect of TGF- $\beta$ on the expression of MMPs in keloid fibroblasts is required.

Growth factors. The majority of keloid research involves the evaluation of protein factors and the signaling pathways that might play a role in keloid formation. A considerable number of cytokines and growth factors is linked to every step in the reaction cascade. According to the manifoldness, many cytokines may play a potential role in keloid pathogenesis. Keloid fibroblasts show an increased number of growth factors and their receptors. Furthermore, keloid fibroblasts also respond more briskly to growth factor-induced signals (3). The derailment of matrix production in keloids is therefore strongly influenced by growth factors. The growth factors TGF- $\beta$ and PDGF play a major role in physiological wound healing. Both factors show significantly abnormal activities in keloid fibroblasts (8). TGF- $\beta$ activates the production of the ECM, and PDGF stimulates cell proliferation and migration. Besides these two important growth factors, other cytokines must be mentioned; basic fibroblast growth factor (FGF) induces angiogenesis, and tumor necrosis factor $\alpha$ (TGF- $\alpha$ ) and interleukin-1 promote inflammation, cell migration and proliferation (31).

TGF- $\beta$ is one of the most well-studied growth factors and seems to play the main role in the pathophysiology of excessive scar formation as found in keloids $(37,90)$. The initial step in the development of a fibrotic reaction in scar tissue is the expression of TGF- $\beta$ by neovascular endothelial cells. They activate adjacent fibroblasts to express elevated levels of TGF- $ß$ as well as type I and VI collagen (91). Keloid fibroblasts are more sensitive to TGF- $\beta$ stimulation and respond to a lower factor concentration compared to normal fibroblasts $(31,92)$. The importance of TGF- $\beta$ was demonstrated by Shah and coworkers. The application of neutralizing antibodies to TGF- $\beta$ resulted in an improved quality of wound healing and a reduced scar tissue formation $(93,94)$. TGF- $\beta$ promotes fibroblast proliferation and synthesis of ECM components (e.g. elastin, fibronectin and collagen type I and III). Matrix growth is stimulated indirectly by TGF- $\beta$ via induction of PDGF. PDGF has been shown to be responsible for an acceleration of granulation tissue formation and for stimulation of collagen production during the later stages of wound healing (31). Keloid fibroblasts also show an increased response to PDGF compared to normal skin fibroblasts (95). Therefore, significantly abnormal activities were observed in keloidal tissue concerning the growth factors TGF- $\beta$ and PDGF (8). In addition to increased cytokine production, keloid fibroblasts also show an increased transcription of the corresponding receptors (30).

Differential TGF- $\beta$ isoforms are expressed during physiological wound healing of the skin and during keloid formation. TGF- $\beta 1$ and $-\beta 2$ are known to have profibrotic properties and TGF- 33 seems to inhibit fibrotic reactions $(30,96)$. TGF- $\beta$ is produced by a variety of different cells. The highest concentrations are found in thrombocytes, the initiating cells of wound closure. The effects of TGF- $\beta$ are mediated through the various receptor types I, II and III. Besides the stimulation of an increased cellular production of ECM components, TGF- $\beta$ also increases the cellular expression of matrix receptor integrin and the synthesis of PAI-1 and TIMP, whereas the expression of collagenase and plasminogen activator (PA) is decreased. This upregulation of inhibitor synthesis and downregulation of protease synthesis further augments the accumulation of ECM proteins, and is the basis for the formation of fibrotic tissue due to excessive action of TGF- $\beta$ (9).

The isoforms TGF- $\beta 1$ and $-\beta 2$ are overexpressed in keloid fibroblasts (3). In addition, increased expression of the TGF- $\beta$ receptor types I and II and an increased phosphorylation of SMAD 3 (and TGF- $B$ associated intracellular signaling molecule) are further features of keloids which support the central role of TGF- $\beta$ in keloid pathogenesis (97).

Although many other growth factors such as epidermal growth factor (EGF), connective tissue growth factor (CTGF), or the previously mentioned fibroblast growth factor (FGF), and tumor necrosis factor $\alpha(\mathrm{TGF}-\alpha)$ have substantial influence on cell growth and differentiation during wound healing, the effects of these factors are contrarily discussed in keloid tissue $(9,31)$. TGF- $\beta$ is a well acknowledged growth factor in keloid formation with extensive scientific focus being placed on this pathway. Interestingly, a recent study by Campaner and coworkers (98) reported that overexpression of TGF-ß1 is an important component in the formation of keloid tissue, but is not as sufficient as an independent factor, providing evidence for the hypothesis that keloid formation is a multifactorial process (38).

\section{Conclusion}

In addition to the above mentioned key factors for keloid formation, various hypotheses have been presented which focus on various details of keloid development. However, to date, the key question regarding keloid formation, whether excessive scar tissue formation is the result of an increased collagen synthesis or due to a reduced breakdown or both, remains unanswered. At present no single unifying hypothesis can be formulated. The multitude of treatment modalities, with no single treatment proven to be widely effective, underlines how little is known about the disease process and indicates the complex and multi-variable pathogenesis of this disease (30).

At present, research evidence indicates that TGF- $\beta$ is one of the main cytokines responsible for stimulating a multitude of signaling mechanisms. The collective release of this growth factor by platelets, lymphocytes, macrophages, endothelial cells and fibroblasts and the divergence of presented explanatory approaches suggest that keloid formation is not due to just one disturbed wound healing process, but that a wide array of subsequent healing mechanisms are involved.

Keloid scarring continues to be a complex and poorly understood subject. A better understanding of growth factor mechanisms, wound matrix degradation and immunologic response is slowly beginning to highlight the complex process of keloid scar formation. Future trends using three-dimensional models for analysis of the mechanical component or the development of animal models (eg. transgenic mice) 
might help to decode the complexity of this subject.

In order to identify more effective therapy regimens and also to advance prevention strategies, we must continue to improve our understanding of the biological mechanisms of scar formation in general and particularly of keloid formation.

\section{References}

1. Alster TS and Williams CM: Treatment of keloid sternotomy scars with $585 \mathrm{~nm}$ flashlamp-pumped pulsed-dye laser. Lancet 345: 1198-1200, 1995.

2. McGrouther DA: Hypertrophic or keloid scars? Eye 8: 200-203, 1994.

3. Slemp AE and Kirschner RE: Keloids and scars: a review of keloids and scars, their pathogenesis, risk factors, and management. Curr Opin Pediatr 18: 396-402, 2006.

4. Atiyeh BS, Costagliola M and Hayek SN: Keloid or hypertrophic scar: the controversy: review of literature. Ann Plast Surg 54: 676-680, 2005

5. Bayat A and McGrouther DA: Clinical management of skin scarring. Skinmed 4: 165-173, 2005.

6. Cohen IK and Peacock EE: Keloids and hypertrophic scars. Plast Surg 1: 732-746, 1990.

7. Mustoe TA, Cooter RD, Gold MH, Hobbs R, Ramelet AA, Shakespeare PG, Stella M, Teot L, Wood FM and Ziegler UE: International clinical recommendations on scar management. Plast Reconstr Surg 110: 560-571, 2002.

8. Al-Attar A, Mess S, Thomassen JM, Kaufmann CL and Davison SP: Keloid pathogenesis and treatment. Plast Reconstr Surg 117: 286-300, 2006.

9. Tuan TL and Nichter LS: The molecular basis of keloid and hypertrophic scar formation. Mol Med Today 4: 19-24, 1998.

10. Diegelmann RF and Evans MC: Wound healing: an overview of acute, fibrotic and delayed healing. Front Biosci 9: 283-289, 2004.

11. Baisch A and Riedel F: Hyperplastic scars and keloids: Part I: Basics and prevention. HNO 54: 893-905, 2006.

12. Singer AJ and Clark RA: Cutaneous wound healing. N Engl J Med 341: 738-746, 1999.

13. Lazarus GS, Cooper DM, Knighton DR, Margolis DJ, Pecoraro RE, Rodehaever G and Robson MC: Definitions and guidelines for assessment of wounds and evaluation of healing. Arch Dermatol 130: 489-493, 1994.

14. Thurston AJ: Of blood, inflammation and gun shot wounds: the history of the control of sepsis. Aust NZ J Surg 70: 855-861, 2000.

15. Artuc M, Hermes B, Steckelings UM, Grutzkau A and Henz BM: Mast cells and their mediators in cutaneous wound healing active participants or innocent bystanders? Exp Dermatol 8: 1-16, 1999.

16. Diegelmann RF, Cohen IK and Kaplan AM: The role of macrophages in wound repair: a review. Plast Reconstr Surg 68: 107-113, 1981.

17. Roberts $\mathrm{AB}$ and Sporn MB: Physiological actions and clinical applications of transforming growth factor-beta (TGF-beta). Growth Factors 8: 1-9, 1993.

18. Philipp K, Riedel F, Sauerbier M, Hörmann K and Germann G: Targeting TGF-beta in human keratinocytes and its potential role in wound healing. Int J Mol Med 14: 589-593, 2004.

19. Clark RA: Fibrin and wound healing. Ann NY Acad Sci 936: 355-367, 2001.

20. Van Winkle W Jr: Wound contraction. Surg Gynecol Obstet 125: $131-142,1967$.

21. Lorenz HP and Longaker MT: Wounds: Biology, Pathology and Management. Stanford University Medical Center, 2008.

22. Greenhalgh DG: The role of apoptosis in wound healing. Int $\mathbf{J}$ Biochem Cell Biol 30: 1019-1030, 1998.

23. Hinz B: Masters and servants of the force: The role of matrix adhesions in myofibroblast force perception and transmission. Eur J Cell Biol 85: 175-181, 2006.

24. Mercandetti M and Cohen AJ: Wound healing: healing and repair. Emedicine.com March 28, 2008.

25. Burd A and Huang L: Hypertrophic response and keloid diathesis: two very different forms of scar. Plast Reconstr Surg 116: $150 \mathrm{e}-157 \mathrm{e}, 2005$.

26. Gillitzer R and Goebeler M: Chemokines in cutaneous wound healing. J Leukoc Biol 69: 513-521, 2001.

27. Cole J, Tsou R, Wallace K, Gibran N and Isik F: Comparison of normal human skin gene expression using cDNA microarrays. Wound Repair Regen 9: 77-85, 2001.
28. Tsou R, Cole JK, Nathens AB, Isik FF, Heimbach DM, Engrav LH and Gibran NS: Analysis of hypertrophic and normal scar gene expression with cDNA microarrays. J Burn Care Rehabil 21: 541-550, 2000.

29. Beausang E, Floyd H, Dunn KW, Orton CI and Ferguson MW: A new quantitative scale for clinical scar assessment. Plast Reconstr Surg 102: 1954-1961, 1998.

30. Butler PD, Longaker MT and Yang GP: Current progress in keloid research and treatment. J Am Coll Surg 206: 731-741, 2008.

31. Niessen FB, Spauwen PH, Schalkwijk J and Kon M: On the nature of hypertrophic scars and keloids: a review. Plast Reconstr Surg 104: 1435-1458, 1999.

32. Peacock EE Jr, Madden JW and Trier WC: Biologic basis for the treatment of keloids and hypertrophic scars. South Med J 63: 755-759, 1970 .

33. Cosman B, Crikelair GF, Ju DMC, Gaulin JC and Lattes R: The surgical treatment of keloids. Plast Reconstr Surg 27: 335-339, 1961.

34. Murray JC: Keloids and hypertrophic scars. Clin Dermatol 12: 27-37, 1994.

35. Murray JC, Pollack SV and Pinnel SR: Keloids: a review. J Am Acad Dermatol 4: 461-470, 1981.

36. Muir IF: On the nature of keloids and hypertrophic scars. Br J Plast Surg 43: 61-69, 1990.

37. Bock O and Mrowietz U: Keloide - Eine dermale fibroproliferative Erkrankung unbekannter Ursache. Der Hautarzt 53: 515-523, 2002.

38. Robles DT, Moore E, Draznin M and Berg D: Keloids: pathophysiology and management. Dermatol Online J 13: 9, 2007.

39. Blackburn WR and Cosman B: Histologic basis of keloid and hypertrophic scar differentiation: clinicopathologic correlation. Arch Pathol 82: 65-71, 1966.

40. Clore JN, Cohen IK and Diegelmann RF: Quantitative assays of types I and III collagen synthesized by keloid biopsies and fibroblasts. Biochem Biophys Acta 586: 384-390, 1979.

41. Ehrlich HP, Desmouliere A, Diegelmann RF, Cohen IK, Compton CC, Garner WL, Kapanci Y and Gabbiani G: Morphological and immunochemical differences between keloid and hypertrophic scars. Am J Pathol 145: 105-113, 1994.

42. Kischer CW and Brody GS: Structure of the collagen nodule from hypertrophic scars and keloids. Scan Electron Microsc 3: 371-376, 1981 .

43. Abergel RP, Pizzurro D, Meeker CA, Lask G, Matsuoka LY, Minor RR, Chu ML and Uitto J: Biochemical composition of the connective tissue in keloids and analysis of collagen metabolism in keloid fibroblast cultures. J Invest Dermatol 84: 384-390, 1985.

44. Bayat A, Arscott G, Ollier WE, Ferguson MW and McGrouther DA: 'Aggressive keloid': a severe variant of familial keloid scarring. J R Soc Med 96: 554-555, 2003.

45. Marneros AG, Norris JE, Watanabe S, Reichenberger E and Owen BR: Genome scans provide evidence for keloid susceptibility loci on chromosomes 2 q23 and 7 p11. J Invest Dermatol 112: 1126-1132, 2004

46. Alhady SM and Sivanantharajah K: Keloids in various races. A review of 175 cases. Plast Reconstr Surg 44: 564-566, 1969.

47. Rossi A and Bozzi M: HLA and keloids: antigenic frequency and therapeutic response. G Ital Dermatol Venereol 124: 341-344, 1989.

48. Lu WS, Wang JF, Yang S, Xiao FL, Quan C, Cheng H, Wang PG, Zhang AP, Cai LQ and Zhang XJ: Association of HLA-DQA1 and DQB1 alleles with keloids in Chinese Hans. J Dermatol Sci 52: 108-117, 2008.

49. Bayat A, Bock O, Mrowietz U, Ollier WE and Ferguson MW: Genetic susceptibility to keloid disease and transforming growth factor beta 2 polymorphisms. Br J Plast Surg 55: 283-286, 2002.

50. Bayat A, Bock O, Mrowietz U, Ollier WE and Ferguson MW: Genetic susceptibility to keloid disease and hypertrophic scarring: transforming growth factor beta 1 common polymorphisms and plasma levels. Plast Reconstr Surg 111: 535-543, 2003.

51. Bayat A, Bock O, Mrowietz U, Ollier WE and Ferguson MW: Genetic susceptibility to keloid disease: transforming growth factor beta receptor gene polymorphisms are not associated with keloid disease. Exp Dermatol 13: 120-124, 2004.

52. Bayat A, Walter JM, Bock O, Mrowietz U, Ollier WE and Ferguson MW: Genetic susceptibility to keloid disease: mutation screening of the TGFbeta3 gene. Br J Plast Surg 58: 914-921, 2005. 
53. Teofoli $\mathrm{P}$, Barduagni S, Ribuffo M, Campanella A, De Pita O and Puddu P: Expression of Bcl-2, p53, c-jun and c-fos protooncogenes in keloids and hypertrophic scars. J Dermatol Sci 22: 31-37, 1999.

54. Tanaka A, Hatoko $M$, Tada $H$, Iioka $H$, Niitsuma $K$ and Miyagawa S: Expression of p53 family in scars. J Dermatol Sci 34: 17-24, 2004

55. Satish L, Lyons-Weiler J, Hebda PA and Wells A: Gene expression patterns in isolated keloid fibroblasts. Wound Repair Regen 14: 463-470, 2006.

56. Lim CP, Phan TT, Lim IJ and Cao X: Stat3 contributes to keloid pathogenesis via promoting collagen production, cell proliferation and migration. Oncogene 25: 5416-5425, 2006.

57. Appleton I, Brown NJ and Willoughby DA: Apoptosis, necrosis and proliferation: possible implication in the etiology of keloids. Am J Pathol 149: 1441-1447, 1996.

58. Luo S, Benathan M, Raffoul W, Panizzon RG and Egloff DV: Abnormal balance between proliferation and apoptotic cell death in fibroblasts derived from keloid lesions. Plast Reconstr Surg 107: 87-96, 2001

59. Sayah DN, Soo C, Shaw WW, Watson J, Messadi D, Longaker MT, Zhang X and Ting K: Downregulation of apoptosis-related genes in keloid tissues. J Surg Res 87: 209-216, 1999.

60. Messadi DV, Le A, Berg S, Jewett A, Wen Z, Kelly P and Bertolami CN: Expression of apoptosis-associated genes by human dermal scar fibroblasts. Wound Repair Regen 7: 511-517, 1999.

61. Seifert O, Bayat A, Geffers R, Dienus K, Buer J, Löfgren S and Matussek A: Identification of unique gene expression patterns within different lesional sites of keloids. Wound Repair Regen 16: 254-265, 2008.

62. Cohen IK, McCoy BJ, Mohanakumar T and Diegelmann RF: Immunoglobulin, complement and histocompatibility antigen studies in keloid patients. Plast Reconstr Surg 63: 689-695, 1979

63. Bloch EF, Hall MG Jr, Denson MJ and Slay-Solomon V: General immune activity in keloid patients. Plast Reconstr Surg 73: 448-451, 1984

64. Kazeem AA: The immunological aspects of keloidal tumor formation. J Surg Oncol 38: 16-18, 1988

65. Kischer CW, Shetlar MR, Shetlar CL and Chrapil M: Immunoglobulins in hypertrophic scars and keloids. Plast Reconstr Surg 71: 821-825, 1983

66. Placik OJ and Lewis VL Jr: Immunologic associations of keloids. Surg Gynecol Obstet 175: 185-193, 1992.

67. Abbas AK, Lichtman AH and Pober JS: Effector mechanism of T-cell-mediated immune response. In: Cellular and Molecular Immunology. 2nd edition, W.B. Saunders, 1994,

68. Fong EP and Bay BH: Keloids - the sebum hypothesis revisited Med Hypotheses 58: 264-269, 2002.

69. Yagi KI, Dafalla AA and Osman AA: Does an immune reaction to sebum in wounds cause keloid scars? Br J Plast Surg 32: 223-225, 1979.

70. Bock O, Schmid-Ott G, Malewski P and Mrowietz U: Quality of life of patients with keloid and hypertrophic scarring. Arch Dermatol Res 297: 433-438, 2006.

71. Crockett DJ: Hypertrophic scars. Br J Plast Surg 17: 245-253, 1964.

72. Curtis AS and Seehar GM: The control of cell division by tension or diffusion. Nature 274: 52-53, 1978.

73. Sussmann MD: Effect on increased tissue traction upon tensile strength of cutaneous incisions in rats. Proc Soc Exp Biol Med 123: 38-41, 1996.

74. Calnan JS and Copenhagen HJ: Autotransplantation of keloid in man. Br J Surg 54: 330-335, 1967.

75. Brody GS, Peng ST and Landel RF: The etiology of hypertrophic scar contracture: another view. Plast Reconstr Surg 67: 673-684, 1981

76. Wang Z, Fong KD, Phan TT, Lim IJ, Longaker MT and Yang GP: Increased transcriptional response to mechanical strain in keloid fibroblasts due to increased focal adhesion complex formation. J Cell Physiol 206: 510-517, 2006.

77. Eckes B, Zigrino P, Kessler D, Holtkötter O, Shephard P, Mauch $C$ and Krieg T: Fibroblast-matrix interactions in wound healing and fibrosis. Matrix Biol 19: 325-332, 2000

78. Hynes RO: Integrins: versality, modulation, and signaling in cell adhesion. Cell 69: 11-25, 1992.
79. Szulgit G, Rudolph R, Wandel A, Tenenhaus M, Panos R and Gardner H: Alterations in fibroblast alphalbeta1 integrin collagen expression in keloids and hypertrophic scars. J Invest Dermatol 118: 409-415, 2002

80. Langholz O, Rockel D, Mauch C, Kozlowska E, Bank I, Krieg T and Eckes B: Collagen and collagenase gene expression in the three-dimensional collagen lattices are differentially regulated by alpha1 beta1 and alpha2 and beta1 integrins. J Cell Biol 131: 1903-1915, 1995.

81. Ravanti L, Heino J, Lopez-Otin C and Kahari VM: Induction of collagenase-3 (MMP-13) expression in human skin fibroblasts by three-dimensional collagen is mediated by p38 mitogenactivated protein kinase. J Biol Chem 174: 2446-2455, 1999.

82. Babu M, Diegelmann R and Oliver N: Keloid fibroblasts exhibit an altered response to TGF-beta. J Invest Dermatol 99: 650-655, 1992.

83. Ravanti L and Kähäri VM: Matrix metalloproteinases in wound repair. Int J Mol Med 6: 391-407, 2000.

84. Lyons RM, Gentry LE, Purchio AF and Moses HL: Mechanisms of activation of latent recombinant transforming growth factor beta 1 by plasmin. J Cell Biol 110: 1361-1367, 1990.

85. Tredget EE, Nedelec B, Scott PG and Ghahary A: Hypertrophic scars, keloids and contractures. The cellular and molecular basis for therapy. Surg Clin North Am 77: 701-730, 1997.

86. Wall SJ, Bevan D, Thomas DW, Harding KG, Edwards DR and Murphy G. Differential expression of matrix metalloproteinases during impaired wound healing of the diabetic mouse. J Invest Dermatol 119: 91-98, 2002.

87. Sadick H, Herberger A, Riedel K, Bran G, Goessler U, Hoermann $\mathrm{K}$ and Riedel F: TGF-betal antisense therapy modulates expression of matrix metalloproteinases in keloidderived fibroblasts. Int J Mol Med 22: 55-60, 2008.

88. Neely AN, Clendening CE, Gardener J, Greenhalgh DG and Warden GD: Gelatinase activity in keloids and hypertrophic scars. Wound Repair Regen 7: 166-171,1999.

89. Fujiwara M, Muragaki Y and Ooshima A: Keloid-derived fibroblasts show increased secretion of factors involved in collagen turnover and depend on matrix metalloproteinase for migration. Br J Dermatol 153: 295-200, 2005.

90. Border WA and Noble NA: Transforming growth factor beta in tissue fibrosis. N Engl J Med 331:1286-1292, 1994.

91. Peltonen J, Hsiao LL, Jaakkola S, Sollberg S, Aumailley M, Timpl R, Chu ML and Uitto J: Activation of collagen gene expression in keloids: Co-localization of type I and VI collagen and transforming growth factor beta 1 mRNA. J Invest Dermatol 97: 240-248, 1991 .

92. Russell SB, Trupin KM, Rodriguez Eaton S, Russell JD and Trupin JS: Reduced growth factor requirement of keloid-derived fibroblasts may account for tumor growth. Proc Natl Acad Sci USA 85: 587-591, 1988.

93. Shah M, Foreman DM and Ferguson MW: Control of scarring in adult wounds by neutralising antibody to transforming growth factor beta. Lancet 339: 213-214, 1992.

94. Shah M, Foreman DM and Ferguson MW: Neutralisation of TGF-beta 1 and TGF-beta 2 or exogenous addition of TGFbeta 3 to cutaneous rat wounds reduces scarring. J Cell Sci 108: 985-1002, 1995.

95. Haisa M, OkochiH and Grotendorst GR: Elevated levels of PDGF alpha receptors in keloid fibroblasts contribute to an enhanced response to PDGF. J Invest Dermatol 103: 560-563, 1994.

96. Bock O, Yu H, Zitron S, Bayat A, Ferguson MW and Mrowietz U: Studies of transforming growth factors beta 1-3 and their receptors I and II in fibroblasts of keloids and hypertrophic scars. Acta Derm Venereol 85: 216-220, 2005.

97. Chin GS, Liu W, Peled Z, Lee TY, Steinbrech DS, Hsu M and Longaker MT: Differential expression of transforming growth factor-beta receptors I and II and activation of Smad 3 in keloid fibroblasts. Plast Reconstr Surg 108: 423-429, 2001.

98. Campaner AB, Ferreira LM, Gragnani A, Bruder JM, Cusick JL and Morgan JR: Upregulation of TGF-beta expression may be necessary but is not sufficient for excessive scarring. J Invest Dermatol 126: 1168-1176, 2006. 